\title{
Aspectos clínico-patológicos associados à circovirose suína no Rio Grande do Sul ${ }^{1}$
}

\author{
André Mendes Ribeiro Corrêa ${ }^{2}$, Caroline Argenta Pescador ${ }^{2}$, Milene Schmitz ${ }^{2}$, \\ Priscila Zlotowski ${ }^{2}$, Daniela Bernadete Rozza ${ }^{2}$, Eduardo Conceição de Oliveira², \\ David Emilio Barcellos ${ }^{3}$ e David Driemeier ${ }^{2 *}$
}

\begin{abstract}
Corrêa A.M.R., Pescador C.A., Schmitz M., Zlotowski P., Rozza D.B., Oliveira E.C., Barcellos D.E. \& Driemeier D. 2006. [Clinical and pathological aspects of swine circovirosis in Rio Grande do Sul, southern Brazil.] Aspectos clínico-patológicos associados à circovirose suína no Rio Grande do Sul. Pesquisa Veterinária Brasileira 26(1):9-13. Setor de Patologia Veterinária, Faculdade de Veterinária, UFRGS, Av. Bento Gonçalves 9090, Porto Alegre, RS 91540-000, Brazil. E-mail: davetpat@ufrgs.br

A total of 97 pigs, which had presented wasting, lymphadenomegaly, respiratory distress and pale or icteric mucosa, was necropsied over a 6-month period. Macroscopic lesions were characterized mostly by enlarged lymph nodes, non collapsed and round edged lungs with cranioventral areas of consolidation and interlobular edema. Kidneys had increased size, were pale, and presented numerous scattered white spots projecting from surface to the cortical area. Some kidneys also showed small red spots similar to petechial hemorrhage over the cortex. Main microscopic lesions were lympho-histiocytic infiltration in lymph nodes, lungs, and kidneys. Immunohistochemical probing with polyclonal antisera to type II swine circovirus stained positively in 50 out of the 56 cases tested (89.2\%).
\end{abstract}

INDEX TERMS: Circovirus, PMWS, PCV2, immunohistochemistry, swine.

RESUMO.- No período de janeiro a julho de 2004, foram realizadas 97 necropsias de suínos que apresentaram subdesenvolvimento, aumento generalizado de linfonodos, palidez ou icterícia de mucosas e, ocasionalmente, problemas respiratórios. As principais lesões macroscópicas encontradas incluíram aumento generalizado de linfonodos, pulmões não colapsados com bordos arredondados e áreas de consolidação, especialmente crânio-ventrais, além de edema de septos interlobulares. Os rins estavam pálidos, aumentados de volume e com pontos brancos que, difusamente distribuídos na superfície, infiltravam em forma de estrias até a zona cortical. Alguns apresentavam pequenos pontos vermelhos, semelhantes a petéquias, difusamente distribuídos no córtex renal. $\mathrm{O}$ achado histológico comum foi a presença, em graus variáveis, de infiltrados linfo-histiocitários em linfonodos, pulmões e rins. O teste imuno-histoquímico utilizando anticorpo

\footnotetext{
${ }^{1}$ Recebido em 16 de março de 2005.

Aceito em 31 de agosto de 2005.

${ }^{2}$ Setor de Patologia Veterinária, Faculdade de Veterinária da UFRGS, Av. Bento Gonçalves 9090, Porto Alegre, RS 91540-000. *Autor para correspondência. E-mail: davetpat@ufrgs.br

${ }^{3}$ Setor de Suínos, Faculdade de Veterinária da UFRGS.
}

policlonal anti-circovírus suíno tipo 2 foi positivo em amostras provenientes de $50(89,2 \%)$ entre 56 suínos examinados.

TERMOS DE INDEXAÇÃO: Circovírus, SMDLD, PCV2, imunohistoquímica, suíno.

\section{INTRODUÇÃO}

O circovírus suíno tipo 2 (PCV2) é um vírus icosaédrico, nãoenvelopado, DNA fita simples com forma circular por ser ligado em suas extremidades (Chae 2004). O PCV2 tem sido incriminado como o principal agente etiológico da síndrome multissistêmica do definhamento do leitão desmamado (SMDLD) (Bolim et al. 2001). A primeira descrição da SMDLD ocorreu em 1991, oeste canadense (Harding 1996). No final da década de noventa, o PCV2 foi associado às lesões de animais afetados (Clark 1997) e diferenciado das amostras virais apatogênicas contaminantes de linhagens PK-15 de cultivo celular (Hamel et al. 1998). Nesse período, foi sugerida a nomenclatura de circovírus suíno tipo 1 (PCV1) para as amostras apatogênicas e circovírus suíno tipo 2, para as amostras virais ligadas à SMDLD e doenças associadas (Allan et al. 1998). Desde então, a SMDLD tem sido descrita em países produtores de suínos em todo o mundo e apresenta caráter emergente (Allan \& Ellis 2000, Sobestiansky et al. 2002). 
No ano de 2001, a SMDLD foi reproduzida em suínos gnotobióticos com a administração intranasal e subcutânea de inóculo contendo unicamente o PCV2 (Bolin et al. 2001). Sabe-se hoje, no entanto, que outros agentes, tais como o parvovírus suíno (PPV) e o vírus da síndrome respiratória e reprodutiva suína (PRRSV), além de diversos outros vírus e bactérias potencializam os casos naturais da SMDLD (Ellis \& Rose 2004). A enfermidade acomete principalmente suínos entre 7 e 15 semanas de idade (Harding 2004). No Brasil, a primeira descrição dessa síndrome foi feita em 2000 , no Estado de Santa Catarina (Ciacci-Zanella 2000), em 2002, na região sudeste (França et al. 2005) e, no Rio Grande do Sul, foi descrita primeiramente em 2003 (Pescador et al. 2003).

Outras condições clínicas e patológicas, como síndrome dermatite nefropatia suína, complexo de doença respiratória, tremor congênito tipo AII, problemas reprodutivos e entéricos são hoje relacionados ao PCV2 (Kim 2004, Segalés et al. 2004). Acredita-se que a transmissão do PCV2 ocorra de forma vertical e horizontal, no entanto, estudos adicionais devem ser realizados para elucidar melhor essa questão (Segalés et al. 2004). O fato do vírus também ser encontrado no sêmen pode colaborar para uma rápida disseminação (Ellis \& Rose 2004). A transmissão vertical pode ser um mecanismo primário de disseminação (Harding 2004). As células alvo do vírus são as células apresentadoras de antígeno e os macrófagos (Chianini et al. 2003). A inflamação granulomatosa dos tecidos linfóides pode ser explicada pela liberação de quimiocinas em resposta à infecção viral, porém o mecanismo completo desse recrutamento histiocitário ainda permanece obscuro (Chae 2004).

O crescimento da suinocultura como atividade econômica envolveu um manejo intensivo, esquema nutricional complexo e o uso de seleção genética visando principalmente a reprodução. Esses fatos, juntamente com a concentração de rebanhos em áreas geográficas restritas, têm sido incriminados como fatores agravantes nos casos de circovirose suína (Sobestiansky et al. 2002). Atualmente não existe um tratamento eficaz contra a circovirose suína. Melhorias no manejo, principalmente na parte sanitária da maternidade e creche com a prática de um regime "todos dentro/todos fora" de vazio sanitário e na diminuição de fatores estressantes como lotação excessiva de baias e má ventilação reduzem significativamente o número de casos da SMDLD (Ciacci-Zanella \& Mores 2001, Ellis \& Rose 2004).

O objetivo deste trabalho foi descrever os achados clínicopatológicos de casos suspeitos de circovirose em suínos provenientes de granjas do estado do Rio Grande do Sul e associá-los com exame imuno-histoquímico de detecção de PCV2.

\section{MATERIAL E MÉTODOS}

Foram necropsiados 97 suínos híbridos provenientes de diversas granjas do Estado do Rio Grande do Sul, com idades entre 5 e 15 semanas, de ambos os sexos, no período de $1^{\circ}$ de janeiro a 31 de julho de 2004 Esses animais apresentaram sinais clínicos compatíveis com a SMDLD que consistiam principalmente de refugagem, apatia e eventualmente tosse, diarréia, anemia e lesões cutâneas. Fragmentos de pele, linfonodos, baço, intestinos, fígado, estômago, rins, pulmão, coração e sistema nervoso central foram coletados, fixados em formalina tamponada a $10 \%$ e processados de acordo com os métodos convencionais para exames histológicos e corados com hematoxilina- eosina (HE) e colorações de Ziehl-Neelsen e Gram pelo método BrownHoops e PAS Ácido Periódico de Schiff (Prophet et al. 1992) foram adotadas em alguns casos.

Fragmentos de linfonodos, pulmão e rim de casos em que foram observadas lesões compatíveis a SMDLD na histologia, ou quando requisitados pelos veterinários, foram submetidos ao exame imunohistoquímico utilizando-se a técnica de avidina-biotina peroxidase (Dako). Anticorpo policlonal anti-PCV2 (Sorden et al. 1999) foi empregado a uma diluição de 1:1000. Utilizou-se como recuperador antigênico Protease XIV (Sigma) e DAB (tetra-hidrocloreto de 3,5diamino-benzidina) (DAKO) como cromógeno.

\section{RESULTADOS}

Os suínos necropsiados apresentavam baixo desempenho corporal (Fig.1), alguns deles com visível estado de caquexia e palidez de mucosas. A caquexia foi considerada quando era notado evidenciação dos processos espinhosos na coluna espinhal. Os principais achados macroscópicos e microscópicos foram observados em linfonodos, baço, rins, pulmões, fígado, intestinos e estômago. Macroscopicamente os linfonodos (Fig.2) e baço estavam aumentados de tamanho. Tanto os linfonodos inguinais

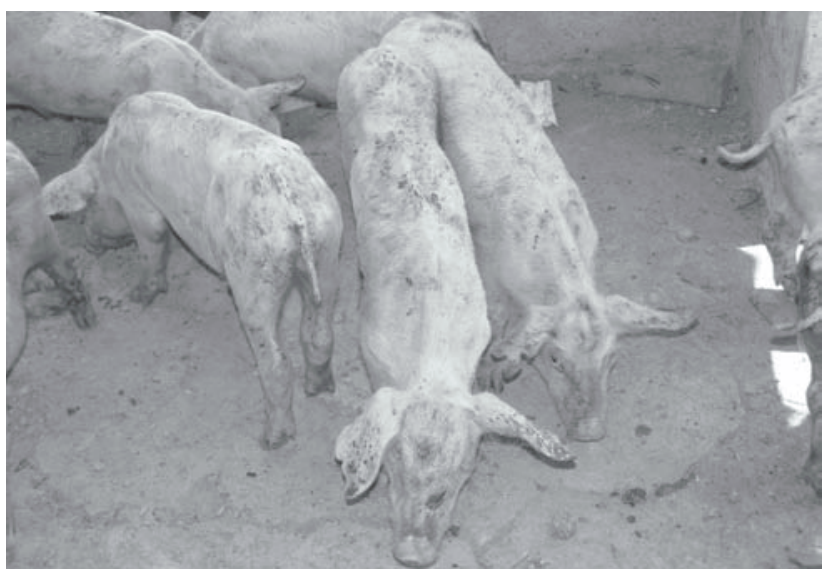

Fig. 1. Circovirose suína. Suínos apresentando mal estado corporal conseqüiente à enfermidade.

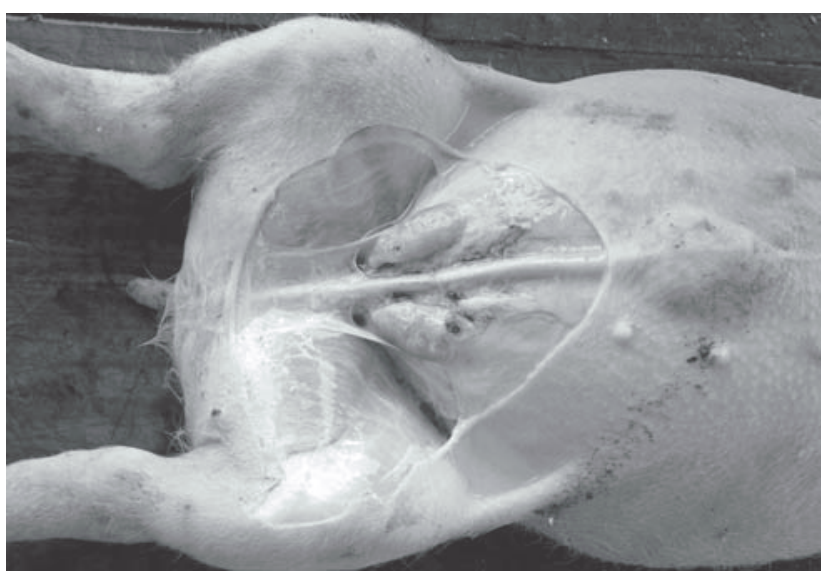

Fig. 2. Linfonodos inguinais aumentados de volume, achado constante de necropsia, na circovirose suína. 
como os linfonodos mesentéricos apresentaram, em alguns casos, aumento de volume acentuado difuso com congestão, hemorragia e áreas multifocais coalescentes com conteúdo de aspecto caseoso. Áreas focais de infarto proeminente e áreas focais de depressão amarelada com aderências de omento foram visualizadas no baço. Os rins, além de aumentados em volume, estavam pálidos e apresentavam pontos brancos de tamanhos variáveis distribuídos aleatoriamente na superfície capsular e que infiltravam, em forma de estrias, a região cortical. Freqüentemente havia pequenos pontos vermelhos, semelhantes a petéquias, distribuídos na superfície subcapsular estendendo-se por toda zona cortical. Diminuição do parênquima hepático, manchas vermelho-escuras e, em alguns casos, icterícia foram as alterações hepáticas mais freqüentes. A serosa intestinal apresentava leve edema, às vezes, conferindo à víscera um aspecto opalescente. Edema difuso de mesentério e evidenciação dos vasos linfáticos pelo seu aspecto branco opalescente e varicoso foram outros achados significantes. No estômago, foram visualizadas áreas de hiperqueratose e ulcerações de graus variados, principalmente na zona do quadrilátero esofágico. Os linfonodos gástricos eram facilmente encontrados e também apresentavam, na maioria dos casos, aumento considerado de volume e edema que freqüentemente se estendia para o pâncreas evidenciando os septos interlobulares. $O$ não colabamento pulmonar foi um achado comum, freqüentemente acompanhado de hidrotórax amarelo-citrino, arredondamento dos bordos, edema interlobular (Fig.3) e evidenciação dos linfonodos traqueobrônquicos e mediastínicos. Áreas de consolidação, predominantemente de distribuição crânio-ventral foi um achado concomitante em vários casos. Apenas quatro suínos apresentaram lesões cutâneas que estavam distribuídas aleatoriamente pelo flanco, abdômen, membros anteriores e posteriores, cabeça e orelhas. As lesões eram circulares com aproximadamente $1 \mathrm{~cm}$ de diâmetro, muitas vezes coalescentes, apresentando-se bem delimitadas por halo avermelhado com elevações da epiderme em forma de crostas.

Lotes de animais provenientes de uma mesma granja apresentavam lesões semelhantes, diferindo das lesões observadas

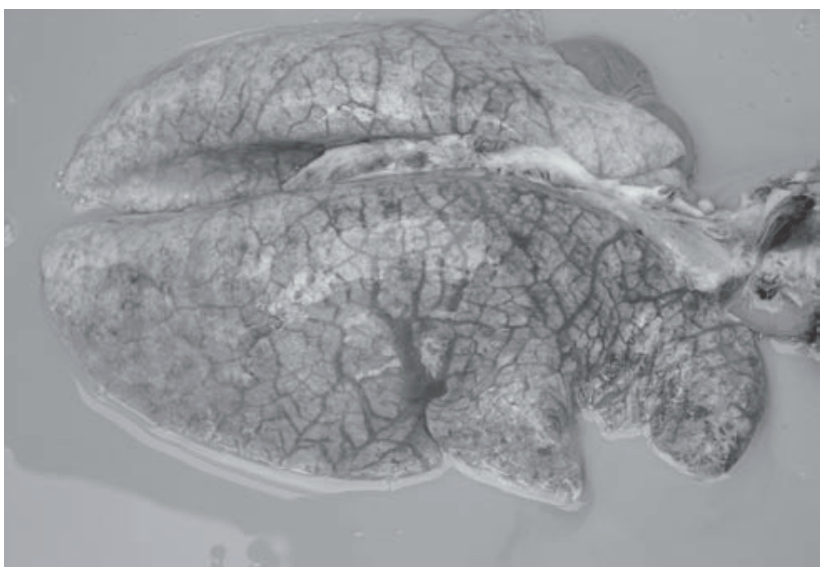

Fig. 3. Pulmão não-colapsado e com acentuado edema interlobular, na circovirose suína.
Quadro 1. Freqüência das principais lesões macroscópicas à necropsia em 97 suínos com circovirose suína

\begin{tabular}{lcc}
\hline Lesões macroscópicas & $\begin{array}{c}\text { Freqüência } \\
(n=97)\end{array}$ & $\%$ \\
\hline Linfonodos aumentados & 78 & 80,4 \\
Pulmões não-colapsados & 64 & 65,9 \\
Linha vertebral marcada & 43 & 44,3 \\
Baço aumentado & 32 & 32,9 \\
Rins aumentados & 31 & 31,9 \\
Fígado manchado & 29 & 29,8 \\
Ascite & 28 & 28,8 \\
Rins com pontos brancos & 26 & 26,8 \\
Ulceração gástrica & 22 & 22,6 \\
Congestão cerebral & 19 & 19,5 \\
Serosite & 17 & 17,5 \\
Enterite & 15 & 15,4 \\
Edema mesentério & 14 & 14,4 \\
Infarto esplênico & 9 & 9,2 \\
Lesões pele & 4 & 4,1
\end{tabular}

em lotes de animais provenientes de outras propriedades. Foram observados lotes distintos com polisserosite, enterite, hepatite e pneumonia bacteriana secundária associada. As principais lesões macroscópicas e suas frequiências foram listadas no Quadro 1.

Nos órgãos linfóides, os achados histopatológicos consistiam principalmente em depleção de linfócitos e edema com perda da arquitetura folicular e presença de um infiltrado linfohistiocitário ou granulomatoso de intensidade variável. Esses infiltrados foram mais evidentes nos seios subcapsulares e medulares e em folículos linfóides, comumente acompanhados de células gigantes e corpúsculos de inclusão intracitoplasmáticos basofílicos de tamanhos e números variados (Fig.4). As inclusões eram PAS positivas e destacavam-se nesta coloração. Os casos de aumento acentuado de linfonodo e baço com áreas escuras ou deprimidas, revelaram na histopatologia trombose de vasos e focos de necrose de coagulação. Nos rins, nefrite intersticial com infiltrado mononuclear difuso, variando de leve a moderado, dilatação de túbulos, fibrose difusa e gotas hialinas

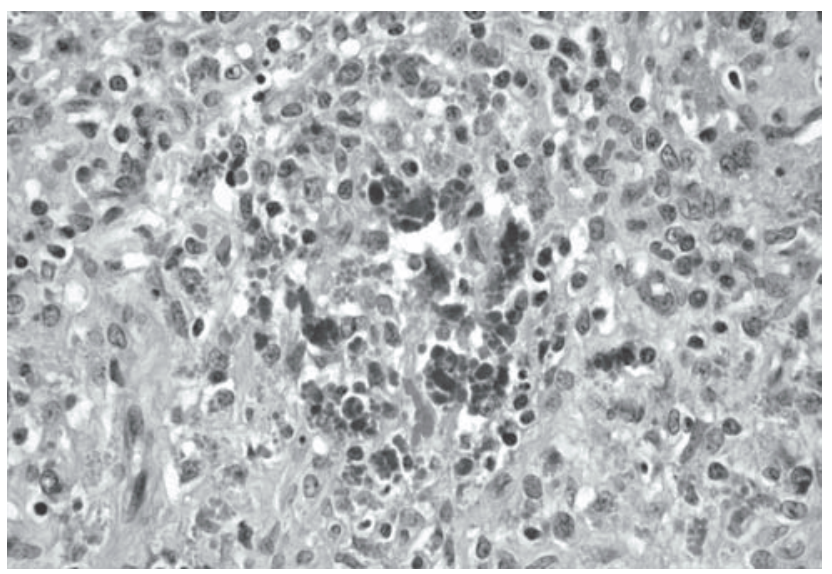

Fig. 4. Linfonodo com infiltrado linfohistiocitário, alguns contendo corpúsculos de inclusão intracitoplasmáticos basofílicos de tamanhos e números variados, na circovirose suína. HE, obj.40. 
nos túbulos foram os achados mais freqüentes. Em poucos casos, glomerulite fibrino-exsudativa com presença de hemácias e plasma no espaço glomerular, juntamente com fibrose intersticial acentuada também foram constatadas. Infiltração linfohistiocitária periportal de intensidade variada, necrose individual de hepatócitos e presença de corpos apoptóticos foram, nessa ordem, as alterações histológicas comuns no fígado. O intestino delgado apresentou principalmente hiperplasia linfóide das placas de Peyer, dilatação dos vasos linfáticos, infiltrado linfohistiocitário ou granulomatoso e infiltração mononuclear na submucosa. Em alguns casos, células gigantes e corpúsculos de inclusão intracitoplasmáticos basofílicos também foram encontrados associados ao tecido linfóide. Pneumonia intersticial com infiltrado misto, predominantemente histiocitário difuso, de intensidade variável, foi observada em 75 animais. Nos casos onde havia lesão cutânea, a epiderme apresentava degeneração hidrópica do epitélio e pústulas intra-epidérmicas. Na derme, infiltrado linfohistiocitário multifocal associado à necrose e vasculite foram os achados comuns nesses casos.

Não foram observadas bactérias álcool ácido resistentes na coloração de Ziehl-Neelsen e também nenhuma bactéria foi encontrada na coloração de Gram dos casos negativos à imuno-histoquímica. As principais lesões microscópicas estão listadas no Quadro 2.

O exame imuno-histoquímico foi realizado em 56 casos suspeitos da SMDLD, resultando em $50(89,2 \%)$ casos positivos (Quadro 3). A marcação foi evidenciada em histiócitos e células gi-

\section{Quadro 2. Freqüência das principais lesões microscópicas à} necropsia em 97 suínos com circovirose suína

\begin{tabular}{lcc}
\hline Lesões macroscópicas & Freqüência & $\%$ \\
\hline \multicolumn{1}{c}{$(n=97)$} & & \\
Linfonodo & 73 & 75,2 \\
$\quad$ Infiltrado histiocitário & 27 & 27,8 \\
$\quad$ Presença de células gigantes & 31 & 31,9 \\
$\quad$ Presença de inclusões & 57 & 58,7 \\
$\quad$ Edema & & \\
Pulmão & 46 & 47,4 \\
$\quad$ Broncopneumonia purulenta & 75 & 77,3 \\
$\quad$ Pneumonia intersticial & & \\
Fígado & 39 & 40,2 \\
$\quad$ Hepatite periportal & 12 & 12,3 \\
$\quad$ Necrose indiv. hepatócitos & & \\
Rim & 35 & 36,0 \\
$\quad$ Nefrite intersticial & 27 & 27,8 \\
$\quad$ Dilatação de túbulos & 10 & 10,3 \\
Proteinúria & 16 & 16,5 \\
$\quad$ Fibrose difusa & 3 & 3,09 \\
$\quad$ Glomerulite fibrino-exsudativa & & 31,9 \\
Intestino delgado & 31 & \\
$\quad$ Dilatação de linfáticos &
\end{tabular}

Quadro 3. Resultado dos exames imuno-histoquímicos de fragmento de linfonodos, pulmão e rim de 56 casos de suínos com circovirose suína

\begin{tabular}{|c|c|c|c|c|c|}
\hline \multirow{2}{*}{$\begin{array}{l}\text { Número } \\
\text { de casos }\end{array}$} & \multirow[t]{2}{*}{ Positivos } & \multirow[t]{2}{*}{ Negativos } & \multicolumn{3}{|c|}{ Marcação positiva por órgão } \\
\hline & & & Linfonodo & Pulmão & Rim \\
\hline 56 & $\begin{array}{c}50 \\
89,2 \%\end{array}$ & $\begin{array}{c}6 \\
10,7 \%\end{array}$ & $\begin{array}{c}47 \\
83,9 \%\end{array}$ & $\begin{array}{c}34 \\
60,7 \%\end{array}$ & $\begin{array}{c}29 \\
51,7 \%\end{array}$ \\
\hline
\end{tabular}

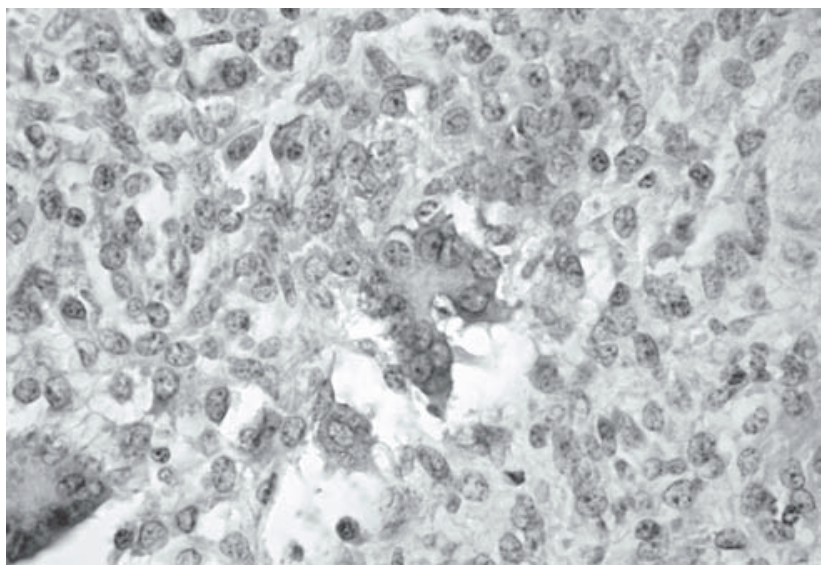

Fig. 5. Circovirose suína. Imuno-histoquímica anti-PCV2. Marcação positiva em células gigantes e histiócitos de linfonodo. Avidinabiotina peroxidase, obj.40

gantes (Fig.5) principalmente nos centros foliculares dos linfonodos, epitélio das glândulas peri-bronquiolares, macrófagos alveolares e no epitélio tubular das alças de Henle e dos túbulos coletores renais. A marcação de antígeno viral estava sempre associada com lesões histológicas nos órgãos.

\section{DISCUSSÃO}

Os achados clínicos e patológicos são compatíveis com os descritos em casos da SMDLD. Marcação positiva na imunohistoquímica foi observada em $89,2 \%$ dos casos avaliados e comprova o envolvimento do vírus. A quantidade de marcação positiva é proporcional à intensidade da doença clínica e também está relacionada com as alterações histopatológicas encontradas em suínos infectados pelo PCV-2 (Krakowka et al. 2005). É importante salientar que esse resultado é influenciado pela metodologia de amostragem, onde foram selecionados, na maioria dos casos, animais com sinais clínicos evidentes da SMDLD. Animais recentemente infectados ou em fase terminal da doença podem apresentar lesões microscópicas moderadas ou ausentes e, conseqüientemente, pequenas quantidades de antígeno de PCV2 podem ser detectadas nos tecidos linfóides (Segalés et al. 2004). Os resultados negativos na imuno-histoquímica podem ser explicados pela variação dos sinais clínicos e faixa etária dos animais analisados neste estudo que incluiu animais caquéticos em fase de crescimento e animais em fase de terminação com apenas retardo no crescimento. Em casos avançados da SMDLD, os sinais clínicos e lesões histológicas podem ser bem evidentes, no entanto, o DNA viral pode estar ausente.

A vasculite necrosante tem sido observada em uma variedade de órgãos, inclusive na derme, sendo responsável pela isquemia e necrose, induzindo lesões macroscópicas e microscópicas na pele. A vasculite necrosante tende a afetar artérias de tamanho pequeno a médio, assim como capilares, com necrose na túnica intima e média. Um infiltrado inflamatório misto nas paredes das artérias também é observado (Segalés \& Domingo 2000). O mecanismo dessa vasculite pode estar relacionado com a hipersensibilidade do tipo III (Segalés 2004). Animais que apre- 
sentam vasculite sistêmica com ausência de lesões de pele e rins são considerados casos atípicos da síndrome dermatite nefropatia suína (Segalés 2004). As lesões de pele normalmente são notadas inicialmente nos membros posteriores e abdômen, mas podem progredir para o tórax, flanco ou orelhas (Harding \& Halbur 2002). Essas lesões cutâneas tendem a coalescer e podem ter distribuição generalizada em animais gravemente afetados. Com o tempo, as lesões ficam cobertas por crostas escuras e desbotam gradualmente (Segalés \& Domingo 2000).

A caquexia e o atraso no crescimento dos animais examinados podem estar relacionados com a proteinúria causada pela lesão renal e com a hiperplasia linfóide e linfangectasia encontradas nos intestinos analisados. Os achados histopatológicos intestinais poderiam explicar, pelo mecanismo de má absorção, as diarréias observadas nesses casos. Essas alterações podem comprometer as defesas antimicrobianas e predispor a infecções bacterianas secundárias (Kim 2004). O quadro de anemia observado em alguns dos animais pode ser relacionado com a perda de sangue e estar fortemente associado às ulcerações gástricas encontradas (Harding 2004). Os achados histopatológicos caracterizam uma doença granulomatosa sistêmica e são comparáveis com outras enfermidades observadas em bovinos tais como intoxicação por polpa cítrica (Gava et al. 1999) e ervilhaca Vicia spp (Barros et al. 2001). O diagnóstico diferencial das lesões histológicas de circovirose deve ser feito em suínos, principalmente frente ao complexo micobacteriose e infecções por Rhodococcus equi (Thoen 1999).

O diagnóstico definitivo dessa síndrome é baseado na presença dos sinais clínicos compatíveis com a doença, achados de lesões microscópicas características em órgãos linfóides e na detecção de antígeno ou ácido nucléico de PCV2 em tecidos através de métodos como imuno-histoquímica e a hibridização in situ (Chae 2004). A análise histológica combinada com a mensuração da infecção viral pela técnica de imuno-histoquímica reflete apuradamente o andamento da relação vírus-hospedeiro (Krakowka et al. 2005). Nos casos descritos, os principais sinais clínicos e as lesões macroscópicas e microscópicas foram características em diversos órgãos e semelhantes às citadas na literatura (Segalés 2004).

Agradecimentos.- Às Técnicas de Laboratório do Setor de Patologia da UFRGS, Ângela Rosaura Belmonte de Souza e Marília Teresinha de Oliveira Belmonte, pelas preparações histológicas. Aos estagiários do Setor de Patologia Veterinária pelo auxílio nas necropsias.

\section{REFERÊNCIAS}

Allan G.M. \& Ellis J. 2000. Porcine circovirus: A review. J. Vet. Diag. Invest. 12(1):3-14.

Allan G. M., McNeilly F., Kennedy S., Daft B., Clarke E. G., Ellis J. A., Haines D.M., Meehan B. M. \& Adair B. M. 1998. Isolation of porcine circoviruslike viruses from pigs with a wasting disease in the USA and Europe. J. Vet. Diag. Invest. 10(1):3-10.

Barros C.S.L., Fighera R.A., Rozza D.B., Rech R.R., Sallis S.V. \& Langohr I.M. 2001. Doença granulomatosa sistêmica em bovinos no Rio Grande do Sul associada ao pastoreio de ervilhaca (Vicia spp). Pesq. Vet. Bras. 21(4):162-171.

Bolin S.R., Stoffregen W.C., Nayar G.P. \& Hamel A.L. 2001. Postweaning multisystemic wasting syndrome induced after experimental inoculation of cesarean-derived, colostrum-deprived piglets with type 2 porcine circovirus. J. Vet. Diagn. Invest. 13(3):185-94.
Chae C. 2004. Postweaning multisystemic wasting syndrome: a review of aetiology, diagnosis and pathology. Vet. J. 168(1):41-9.

Chianini F., Majo, N., Segalés J., Dominguez, J. \& Domingo M. 2003. Immunohistochemical characterisation of PCV2 associate lesions in lymphoid and non-lymphoid tissues of pigs with natural postweaning multisystemic wasting syndrome (PMWS). Vet. Immunol. Immunopathol. 94(1-2):63-75.

Ciacci-Zanella J. R. 2001. Doenças emergentes na suinocultura: Circovirose suína. Anais do X Congresso Brasileiro de Veterinários Especialistas em Suínos (ABRAVES). Porto Alegre. p.122-127.

Ciacci-Zanella J. R. \& Morés N. 2000. Síndrome multissistêmica do definhamento do leitão desmamado (SMDLD) causada por circovírus suíno. Memória Congresso Mercosur de Producción Porcina, Buenos Aires, p.EIP16.

Clark E. 1997. Post-weaning multisystemic wasting syndrome. Proc. Am. Assoc. Swine Pract. 28:499-501.

Ellis J.A. \& Rose N. 2004. The role of co-fators in the pathogenesis of PCV2associated diseases. PCV2 diseases. Merial, Hamburg (From research back to the field again). 18th IPVS, p.79-94.

França T.N., Peixoto P.V., Brito M.F., Mores N., Zanella J. \& Driemeier D. 2005. Surto de Circovirose (Síndrome do Definhamento Multissistêmico de Suínos Desmamados) no estado do Rio de Janeiro. Pesq. Vet. Bras. 25(1):39-53.

Gava A., Barros C.S.L., Sousa R.S. \& Traverso S.D. 1999. Polpa cítrica como causa de mortalidade em bovinos no Brasil. Anais do $9^{\circ}$ Encontro Nacional de Patologia Veterinária (Enapave), Belo Horizonte, p.76.

Hamel A.L., Lin L.L., Nayar G.P. 1998. Nucleotide sequence of porcine circovirus associated with postweaning multisystemic wasting syndrome in pigs. J.Virol. 72:5262-5267.

Harding J.C. 1996. Post-weaning multisystemic wasting syndrome: Preliminary epidemiology and clinical findings. Proc. West. Can. Assoc. Swine Pratic, p.21.

Harding J.C. 2004. The clinical expression and emergence of porcine circovirus 2. Vet. Microbiol. 98(2):131-5.

Harding J.C. \& Halbur P.G. 2002. PMWS or a group of PCV2-associated syndromes: Ever-Growing concerns. PMWS and PCV2 diseases. Keynotes on Merial Symposium and brief epidemiological updates, p.19-32.

Kim J., Ha Y., Jung K., Choi C. \& Chae C. 2004. Enteritis associated with porcine circovirus 2 in pigs. Can. J. Vet. Res. 68(3):218-21.

Krakowka S., Ellis J., McNeilly F., Waldner C. \& Allan G. 2005. Features of porcine circovirus- 2 disease: correlations between lesions, amount and distribution of virus, and clinical outcome. J. Vet. Diagn. Invest. 17(3):213-22.

Pescador C., Rozza D.B., Zlotowski P., Borowski S.M., Barcellos D.E.S.N. \& Driemeier D. 2003. Principais lesões histológicas associadas a circovirose em suínos das fases de crescimento e terminação em rebanhos do Rio Grande do Sul. Anais XI Congr. Bras. Vet. Esp. em Suínos (Abraves), Goiânia, p.105-106.

Prophet E.B., Mills B., Arrington J.B. \& Sobin L.H. 1992. Laboratory Methods in Histotechnology. Armed Forces Institute of Pathology, American Registry of Pathology, Washington, DC. 279p.

Segalés J. \& Domingo M. 2000. Porcine dermatitis and nephropathy syndrome: a porcine circovirus type 2 infection disease? Merial 16th PMWS Symposium, Melbourne, p.21-31.

Segalés J., Rosell C. \& Domingo M. 2004. Pathological findings associated with naturally acquired porcine circovirus type 2 associated disease. Vet. Microbiol. 98:137-149.

Sobestiansky J., Barbadino Jr P., Seyboth L. \& Matos M. 2002. Circovirose suína e Circovírus suíno, p.5-51. In: Sanidade em Foco 3. Pfizer, Goiânia.

Sorden S.D., Harms P.A., Nawagitgul P., Cavanaugh D. \& Paul P.S. 1999. Development of polyclonal-antibody-based immunohistochemical method for the detection of type 2 porcine circovirus in formalin-fixed, paraffin-embedded tissue. J. Vet. Diagn. Invest. 11(6):528-30.

Thoen C.O. 1999. Tuberculosis, p.627-630. In: Leman A.D., Straw B.E., Mengeling W.L., D’Allaire S. \& Taylor D.J. (ed.) Diseases of Swine. 8th ed. Iowa State University Press, Ames. 